\title{
Estudio estratigráfico y de correspondencia de los paramentos decorativos de la escalera de la Santa Cueva de Cádiz.
}

\section{Definición del Proyecto de Intervención}

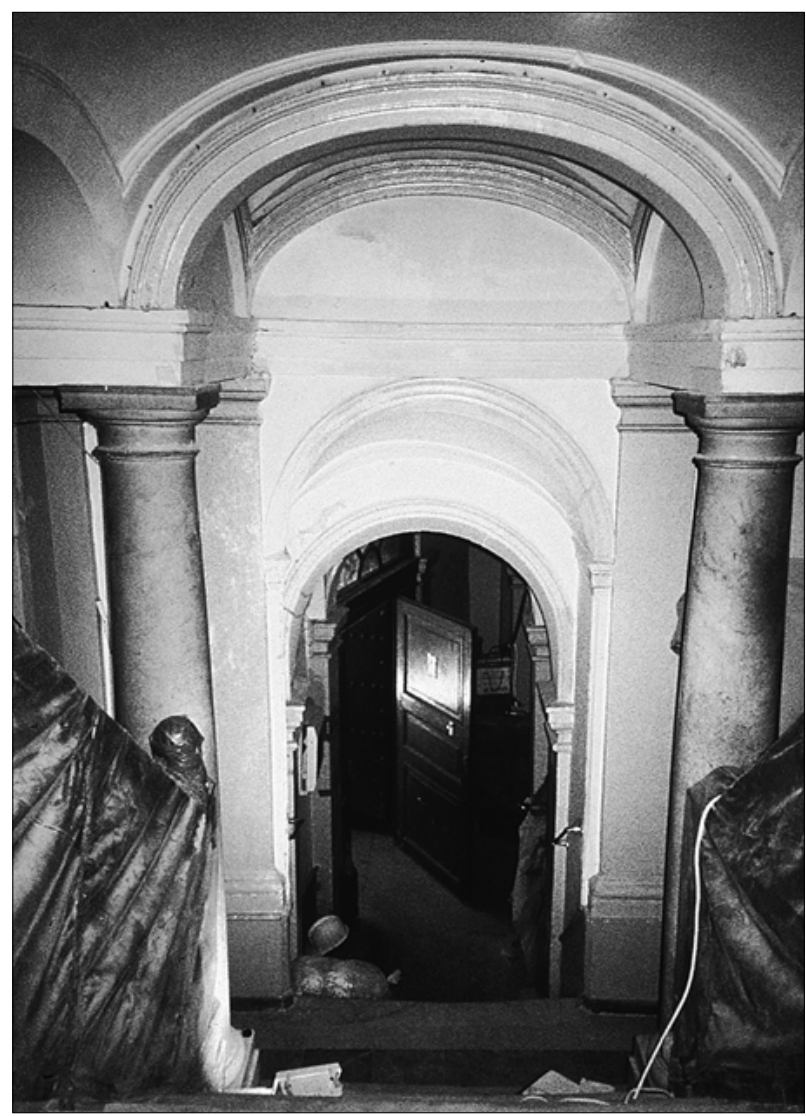

$\mathrm{M}^{\mathrm{a}}$ Isabel Fernández Medina Conservadora-Restauradora del Centro de Intervención del IAPH

Ma José González López Asesora Técnica en ConservaciónRestauración del Centro de Intervención del IAPH

Gracia Montero Saucedo Conservadora-Restauradora del Centro de Intervención del IAPH

\section{Introducción}

El templo de la Santa Cueva situado en la calle Rosario es un conjunto histórico artístico compuesto de una capilla baja o subterránea, dedicada a la meditación de la Pasión de Cristo, y de otra alta, u oratorio, consagrado al Santísimo Sacramento. Su construcción se llevó a cabo en la segunda mitad del siglo XVIII en estilo clasicista o neoclásico. El día 31 de marzo de 1796 se bendijo e inauguró el oratorio, culminándose la obra del conjunto.

Las obras derivadas de la intervención arquitectónica que se está llevando a cabo en este inmueble como consecuencia del Convenio suscrito entre la Consejería de Cultura de la Junta de Andalucía, la Fundación Caja Madrid y el Arzobispado de Cádiz firmado en dicha el 9 de septiembre de 1997, han puesto de manifiesto la presencia de decoraciones pictóricas subya- 
centes en los paramentos de la escalera de acceso al Oratorio Alto y de descenso a la Cripta. Este hecho se ha manifestado una vez retirada las molduras de madera ubicadas en las esquinas de los arcos de acceso al Oratorio, lo que ha motivado las primeras catas estratigráficas y la necesidad de desarrollar el estudio estratigráfico y de correspondencia de este ámbito, y de consecuencia, elaborar el proyecto de recuperación de los paramentos marmóreos decorativos.

La realización de este estudio antes de la intervención arquitectónica en los paramentos de estos espacios ha permitido conocer con precisión la decoración marmórea subyacente a los revestimientos pictóricos actuales, su correspondencia, estado de conservación y la definición de la metodología de tratamiento y de recuperación de la decoración original, además de su cuantificación económica, como desarrollaremos a lo largo de este artículo.

\section{Descripción de la situación actual}

En el momento de su construcción, las escaleras de acceso a la cripta y las de subida al oratorio fueron decoradas en paramentos, bóvedas y cornisas con estucos marmoreados que desarrollan composiciones con elementos moldurados, formando juegos de recuadros y destacando esquinas y centro.

El cambio en los gustos estéticos en el tiempo ha modificado el aspecto original de este ámbito arquitectónico, quedando ocultos los estucos marmóreos por una o varias capas de recubrimientos monocromos.

La decoración actual consiste en recubrimientos de pinturas al temple o sintéticas en blanco y tonalidad ocre verdosa que recubren la totalidad de los paramentos de las escaleras de este monumento.

Tanto en la escalera de acceso a la cripta como en la de subida al oratorio, los pilares, pilastras y molduras han sido cubiertos por un estrato uniforme de tonalidad ocre, mientras que los paramentos, bóvedas y cúpula, presentan un recubrimiento blanco en superficie. El zócalo ha sido decorado en tono rosáceo en la zona de subida al oratorio y en gris oscuro en la de acceso a la cripta.

\section{Objetivos}

Los objetivos de este estudio son diversos y están encaminados al conocimiento de la secuencia de estratos existentes en los paramentos. Para ello se ha aplicado la metodología de estudio estratigráfico y de correspondencia que tradicionalmente se viene aplicando con éxito tanto en escultura policromada como a cualquier bien cultural que presente en su composición varios estratos pictóricos o decorativos superpuestos .

Esta metodología de estudio ha permitido individualizar aquellos datos de interés necesarios con vistas al conocimiento de la superposición decorativa presente y también y más importante, para poder efectuar una valoración crítica y conceptual del alcance de la intervención que se propone para estos ámbitos, sustentada con elementos de juicio fiables y cuantificables.

Los objetivos de la realización de este estudio estratigráfico han sido de índole diversa:

\section{De conocimiento:}

- Conocimiento de los distintos estratos que conforman las capas de estuco marmoreado y de las pinturas que lo recubren.

- Determinar las características técnicas de cada uno de los estratos.

- Establecer las secuencias decorativas en los diferentes elementos arquitectónicos: paramentos, pilastras, pilares, cornisas, zócalo, bóvedas.

- Analizar el estado de conservación de la decoración marmórea subyacente.

- Determinar el porcentaje de decoración subyacente existente

\section{De intervención:}

- Evaluar la intervención propuesta con criterios basados en los resultados obtenidos de los estudios realizados.

- Poner a punto la metodología de remoción de estratos superpuestos.

- Individualizar los tratamientos y los productos más adecuados, así como la metodología de aplicación.

- La puesta en valor de los estucos en función de los datos extraídos de este informe.

\section{Técnica de ejecución de los estucos marmóreos}

Las técnicas de realización de estucos marmóreos aparecen en Alemania en el siglo XVII por influencia del Renacimiento italiano. Sólo se consideraban adecuadas para decoraciones de interiores.

Los estucados se realizaban con yeso alúmbrico puro o de alabastro, cola y colorantes y no se añadían áridos.

En cuanto a la dureza, el mármol imitado apenas supera al natural. Los pigmentos empleados debían ser resistentes a la luz y a la cal.

\section{Proceso de realización:}

Las referencias encontradas en la bibliografía consultada han puesto en evidencia la técnica de decoración que generalmente se empleaba en la ejecución de decoraciones marmóreas efectuadas en estuco, los materiales, y formas de acabado.

Ignacio Garate Rojas en su monografía "El arte de la cal" nos indica como se prepara la pasta del estuco y la forma de aplicar el veteado para imitar al mármol:

Correspondiendo a la estructura y coloración de la muestra, se empezaban a preparar con la pasta del es- 
tuco varias masas de color de mármol, con ligeras variaciones de tonalidad; éstos serían los tonos fundamentales. Con estas masas se realizaban después las mezclas para las tonalidades de las distintas partes del estuco.

Para el veteado se preparaba una pasta fluida de yeso alúmbrico en blanco, rojo o amarillo, según las vetas dominantes del tipo de mármol a imitar.

Posteriormente se practicaban unas hendiduras en las masas antes preparadas y se vertían en ellas los colores del veteado.

En relación con los pigmentos presentes en los estucos Ramón Pasqual Diez nos precisa los colores que mejor se comportan en esta técnica.

Los colores minerales son los mejores, aunque en alguna ocasión podrán usarse otros: los de común uso son, el albín, el pavonazo, carmín ordinario, la tierra roxa, el bol, ocre tostado, y por tostar, la tierra de hombre, los polvos de imprenta, el oropimente; el añil, el minio y bermellón también suelen usarse. De estos y otros colores suele tener noticia el Maestro, y saber la correspondencia de unos con otros.

Cada uno de los colores dichos componen varios colores, y de la mezcla de unos con otros resultan otros muchos; por ejemplo, del añil y carmín sale el morado claro ú oscuro, según se quiere; del oropimente y añil resultan muchos verdes, y así de otros.

En cuanto al tratamiento de la superficie encontramos referencias precisas en Frazzoni, D.

Se pueden conseguir superficies lisas y pulidas mezclando carbonato cálcico y pigmentos resistentes, o bien a base de cal en pasta y carbonato cálcico, estos últimos se llaman estucos pulidos y son normalmente los más económicos.

Para obtener una superficie mural lisa y pulida, que imite la superficie del mármol, hay que emplear las siguientes proporciones.

a. Se aplican los primeros estratos de cal sobre los ladrillos limpios del muro. El mortero para esta primera capa puede tener las mismas proporciones que el intonaco común, es decir, cal hidráulica o cal oscura y arena, que tiene mayor poder de adhesión y dureza que la cal blanca y arena. Cuando no sea posible se puede emplear un intónaco de cal blanca y arena, pero habrá que esperar más a que seque.

b. Una vez realizada esta primera fase y endurecido el intónaco, se aplica una nueva capa de cal blanca apagada y polvo de mármol en proporciones iguales, reservando un último estrato muy fino compuesto por mitad de cal y mitad de polvo de mármol, que se bañará con agua de jabón preferiblemente oleoso.

c. La superficie obtenida será pulida y planchada en frío, y después de dos horas se planchará de nuevo, esta vez en caliente. Una vez realizada esta operación se baña la superficie obtenida con agua de jabón oleoso. Cuanto más se bañe la superficie y se insista con el planchado en caliente, mayor grado de pulido y dureza adquiere el acabado.

Sobre esta superficie se pueden aplicar colores como imitación de marmoreados. La composición de los colores al fresco se obtiene sólo con agua aplicados sobre un intónaco de cal blanca y polvo de mármol (carbonato de cal) en partes iguales inmediatamente después de ser realizado. Para que el color adquiera mayor resistencia se debe aplicar después de haber sido planchado en frío el intónaco, seguidamente se pule, pudiendo ser pulida también la capa de color.

En los estucos marmóreos de la Santa Cueva encontramos la combinación de dos técnicas de ejecución diferentes. Ambas tienen en común que están realizadas sobre un mortero inferior de granulometría uniforme (carbonato cálcico y cuarzo) sobre el que se aplica un enlucido fino (carbonato cálcico y trazas de cuarzo). En paramentos y bóvedas éste es de color rosáceo y sirve de base a la decoración, sobre él se aplica mediante veladuras, posiblemente realizadas a la cal, un veteado para obtener el efecto marmóreo característico de este material. Sin embargo en pilares, pilastras y cornisas, el enlucido de base es blanco-amarillento sobre el que se realiza en seco la superposición de capas de color y veladuras que imitan el veteado del mármol.

\section{Estudios preliminares para la definición del Proyecto de Intervención}

El estudio de correspondencia de capas pictóricas nos permite conocer en profundidad todos los estratos constitutivos de una obra, su localización y correspondencia, lo que adquiere especial relevancia a la hora de disponer de elementos de juicio suficientes para definir los criterios de actuación sobre una obra con superposiciones decorativas. Entendiéndose por éstas la superposición total o parcial de un estrato pictórico o decorativo intencionado con la finalidad de adecuarse a los cambios estético o a las modas imperantes en un determinado momento histórico del bien cultural.

El conocimiento del número de estratos existentes y las características técnicas de éstos son datos importantes para la elección del sistema de remoción de dichos estratos, y la preservación de la capa pictórica original subyacente, ya que la aplicación de una metodología de remoción agresiva o poco idónea puede ser un factor importante de degradación.

Con el objeto de definir el método de trabajo más adecuado y una vez conocidos los estratos existentes, es necesaria la realización de pruebas de remoción de cada uno de ellos, como pruebas de resistencia al agua, pruebas de eliminación mecánica y test de disolventes.

En el caso de que la eliminación de los estratos se realizara mecánicamente, debemos asegurarnos que este método no causará daños innecesarios al original por la acción mecánica del instrumental empleado, en 
Foto I. Catas decoración marmórea subyacente en la bóveda.

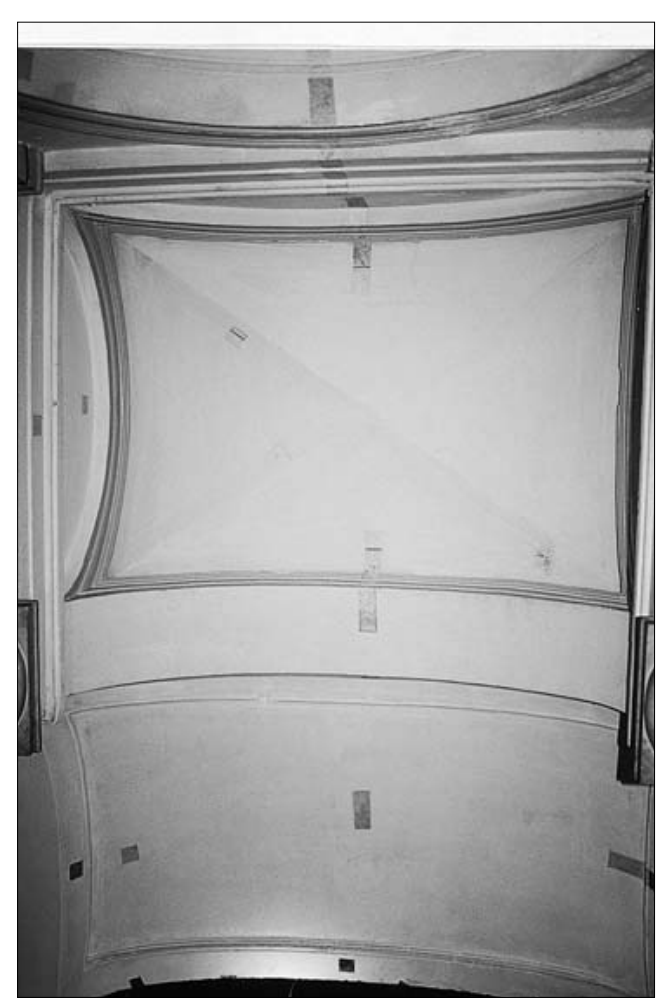

cuyo caso debemos recurrir a medios químicos que combinados con los mecánicos puede resultar la metodología más adecuada.

Para definir el alcance y el tipo de intervención en el caso específico de la decoración de la escalera de la Santa Cueva se han realizado los siguientes estudios preliminares con objeto de cumplir con los objetivos de conocimiento anteriormente expresados:

I. Estudio estratigráfico y de correspondencia de capas pictóricas

2. Estudio de las secuencias decorativas en los diferentes elementos arquitectónicos.

3. Evaluación del porcentaje de la decoración original subyacente a la actual.

4. Determinación del estado de conservación.

5. Test de disolventes y descripción de la metodología para la remoción de la decoración actual.

\section{Estudio estratigráfico y de correspondencia de capas pictóricas}

El estudio estratigráfico y de correspondencia de capas pictóricas tiene su origen en el examen material de esculturas en madera policromada que presentan superposición de varias policromías. Este método empieza a desarrollarse en el IRPA (Instituto Real del Patrimonio Artístico) de Bruselas por Agnés Ballestrem en la década de los 70, quien lleva a cabo los primeros estudios de estratos policromos en esculturas, siguiendo la metodología de estudios estratigráficos aplicada en arqueología.
Con este estudio se consigue determinar el número de policromías existentes en una obra, así como conocer el estado de conservación y técnica de ejecución de cada una de ellas, lo que quedará recogido en un gráfico de correspondencias, indicando su orden cronológico y la superficie que ocupan. Ello nos permite conocer la evolución en el tiempo de una obra, los cambios estéticos que ha sufrido, el estado en el que se encuentra actualmente, la reconstrucción secuencial de la evolución polícroma sufrida por la escultura a través de su historia material.

Este estudio se inicia con la observación con lupa binocular de los bordes de las lagunas existentes para posteriormente determinar la necesidad de realizar "ventanas de estudio" de sólo unos milímetros, localizadas en zonas poco visibles y que puedan proporcionar datos de interés. Siguiendo esta metodología se va configurando el mapa de las policromías existentes y se va reconstruyendo la historia material de la obra objeto de estudio.

La aplicación del estudio estratigráfico y de correspondencia aplicado al conocimiento de estratos pictóricos en los paramentos, fachadas, etc. de un inmueble exige la puesta a punto de una metodología de conocimiento específica que, si bien está basada en el estudio de capas polícromas escultóricas, exige por las características del inmueble una variación del método general, sobre todo si tenemos en consideración la amplitud de los espacios a estudiar y la posibilidad de efectuar catas estratigráficas de mayor dimensión que cuando se realiza este estudio sobre un bien cultural escultórico o pictórico, en el cual la superficie es mucho más reducida y exige la realización de microcatas con un instrumento de aumento de precisión (lupa binocular prismática).

La metodología de estudio aplicada a estos espacios arquitectónicos se ha individuado en dos fases diferentes pero complementaria: por un lado se ha realizado el estudio estratigráfico y de correspondencia de los estratos existentes (paramentos, pilastras, pilares, cornisas, zócalo y bóvedas) y por otro el estudio de las secuencias decorativas en los diferentes elementos arquitectónicos.

Ello ha exigido la realización de catas locales de $5 \times 5 \mathrm{~cm}$ para establecer la presencia y número de estratos y su relativa correspondencia y posteriormente,una vez individuada las zonas de interés, se llevaron a cabo catas secuenciales entre los diversos elementos arquitectónicos para determinar la secuencia decorativa de cada uno de ellos. Las dimensiones de estas catas fueron variables en función de la zona de estudio (Véase foto $n^{\circ} \mathrm{I}$ ).

\section{I.I Estudio estratigráfico}

Se ha realizado mediante catas estratigráficas en zonas de interés a fin de conocer la secuencia de estratos pictóricos de cada uno de los elementos arquitectónicos. Los resultados de las catas efectuadas se describen a continuación: 


\section{Cata $n^{\circ} \mathrm{I}$}

Paramentos de la escalera de subida al oratorio.

Aparecen tres estratos, un primer estrato en superficie de color blanco (pintura al temple),el segundo de color gris (pintura sintética) y un tercer estrato subyacente que se identifica como un estuco marmóreo en tonos rojos, tierras y ocres (Véase foto $n^{\circ} 2$ ).

\section{Cata $\mathrm{n}^{\circ} 2$}

Zócalo de la escalera de subida al oratorio.

Se han localizan cuatro estratos superpuestos. El primero de color rosado (pintura sintética), el segundo de tonalidad ocre (pintura sintética), seguido de otro estrato de color ocre verdoso (pintura sintética) y un cuarto estrato de estuco marmoreado en color rojo oscuro.

\section{Cata $n^{\circ} 3$}

Pilastras de la escalera de subida al oratorio.

En esta cata aparecen dos estratos. El primero de ellos es de color ocre verdoso (pintura sintética) y subyacente a éste aparece un estuco marmóreo de color amarillo veteado en gris.

\section{Cata $n^{\circ} 4$ y 5}

Cúpula y cornisa en la escalera de acceso a la cripta. Se han realizado dos catas una en la cúpula y otra en la cornisa decorativa de la misma cúpula. En la cúpula aparecen tres estratos de pintura al temple en diferentes tonalidades. El que encontramos en superficie es de color blanco, seguido de un estrato gris claro y un tercero gris más oscuro. En la cornisa se encuentra la misma serie estratigráfica más un estrato superficial de color ocre (pintura sintética).

\section{I.2 Estudio de correspondencia de capas pictóricas}

Tras la realización y el estudio de las catas estratigráficas se ha elaborado la carta de correspondencia de capas pictóricas a fin de poner de manifiesto la correspondencia de estratos entre los diferentes elementos

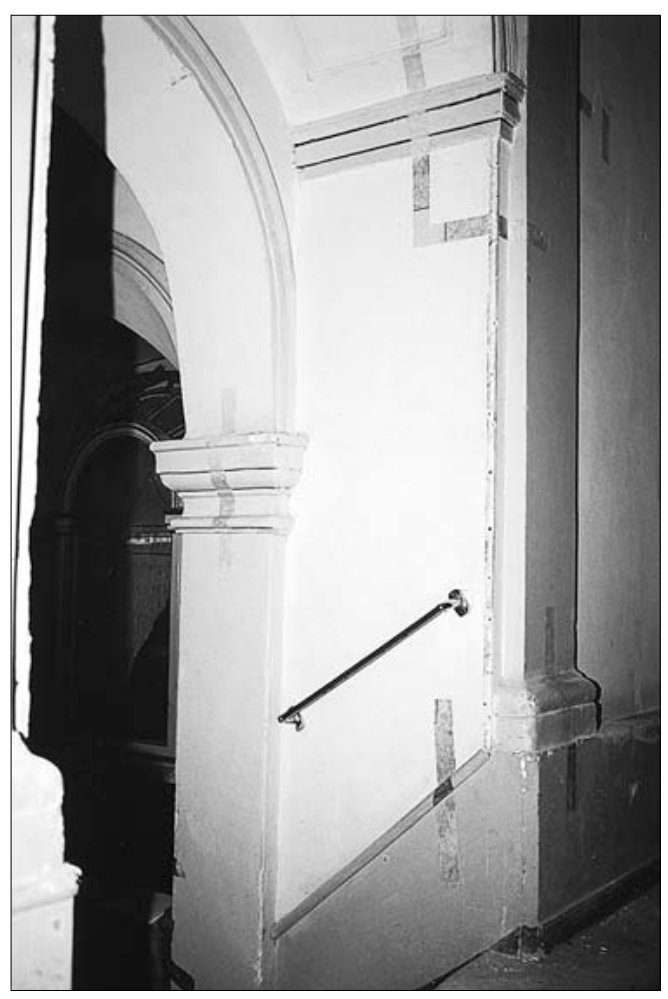

arquitectónicos que conforman el ámbito objeto de estudio. Los resultados se exponen a continuación:

\section{Escalera de subida al oratorio}

Encontramos un estrato subyacente de estucos marmóreos localizados en los paramentos, bóvedas, zócalo y pilastras. Sobre éste se han aplicado en intervenciones posteriores dos recubrimientos, blanco y gris respectivamente, en paramentos y bóvedas y de color ocre verdoso sobre pilastras y molduras.

Los resultados de este estudio se indica en la siguiente tabla:

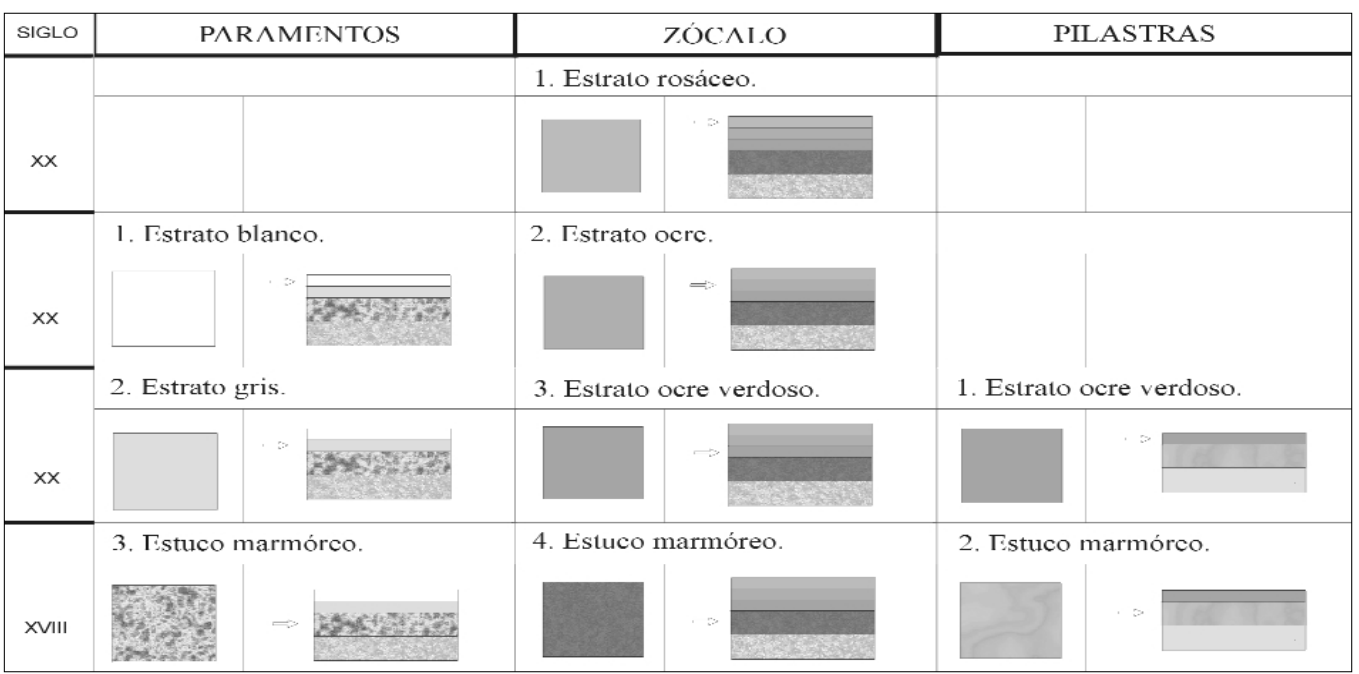


$\frac{1}{\square}$

\section{Escalera de acceso a la cripta}

En los paramentos, cúpula y cornisas aparece un estrato subyacente gris oscuro. Sobre éste se encuentran varios recubrimientos en blanco y gris claro. En los pilares y pilastras el estrato subyacente es un estuco marmóreo, sobre el que aparece un recubrimiento en ocre.

Los resultados se indican a continuación:

Estudio de correspondencia de capas pictóricas. ESCALERA DE ACCESO A LA CRIPTA

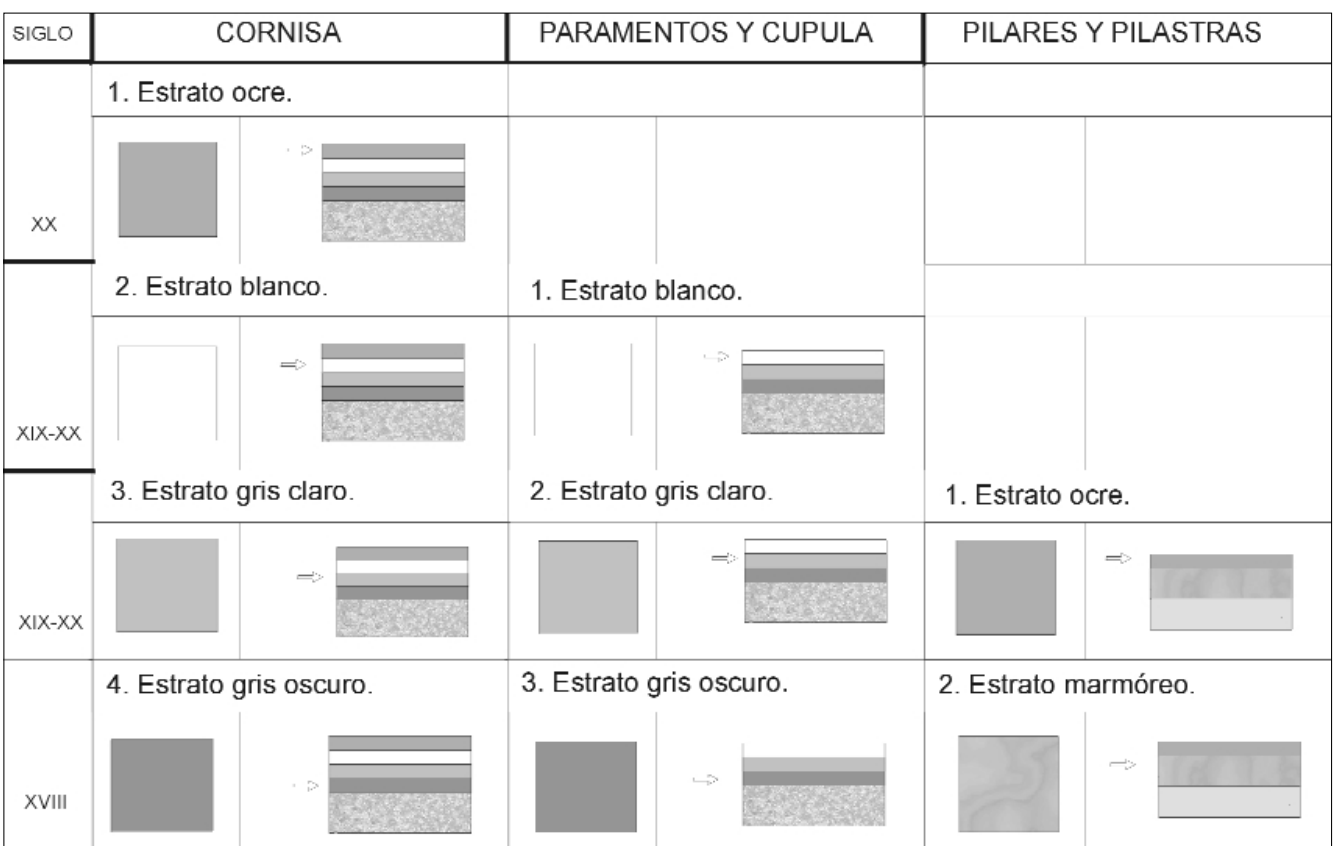

Foto 3 . Secuencia decorativa del original. Paramentos de acceso Oratorio

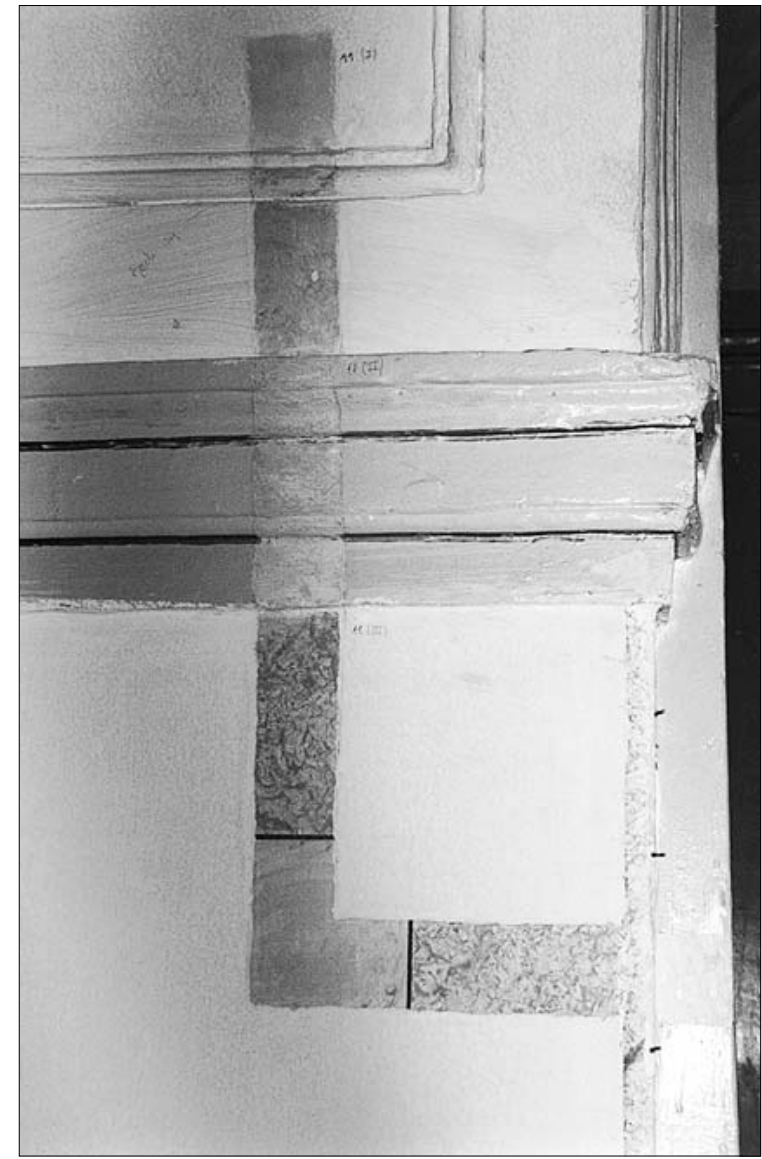

El estudio conjunto de los resultados de ambas fases de este estudio (estratigráfico y de correspondencia) ha permitido llegar a la siguiente conclusión:

Con los datos disponibles hasta el momento podemos afirmar que la escalera de subida al oratorio fue decorada en el siglo XVIII con estucos marmóreos en su totalidad, mientras que en la escalera de acceso a la cripta la decoración encontrada es un recubrimiento gris al temple, excepto en pilares y pilastras tratadas con estucos marmóreos, así como las molduras de las puertas de ingreso a la cripta, en las que los marmorizados aún aparecen visibles actualmente. En épocas posteriores se realizaron diversas decoraciones o recubrimientos pictóricos sobre los estucos originales realizadas de forma monocromática y con pintura sintética fundamentalmente.

2. Estudio de las secuencias decorativas en los diferentes elementos arquitectónicos

Este estudio se ha llevado a cabo mediante la realización de catas en zonas de transición entre los diferentes elementos arquitectónicos, cornisas, paramentos, molduras, zócalo y bóvedas. En total se han realizado 15 catas de 5 centímetros de ancho y entre 20 y 75 centímetros de largo (Véase foto $\left.n^{\circ} 3\right)$. 


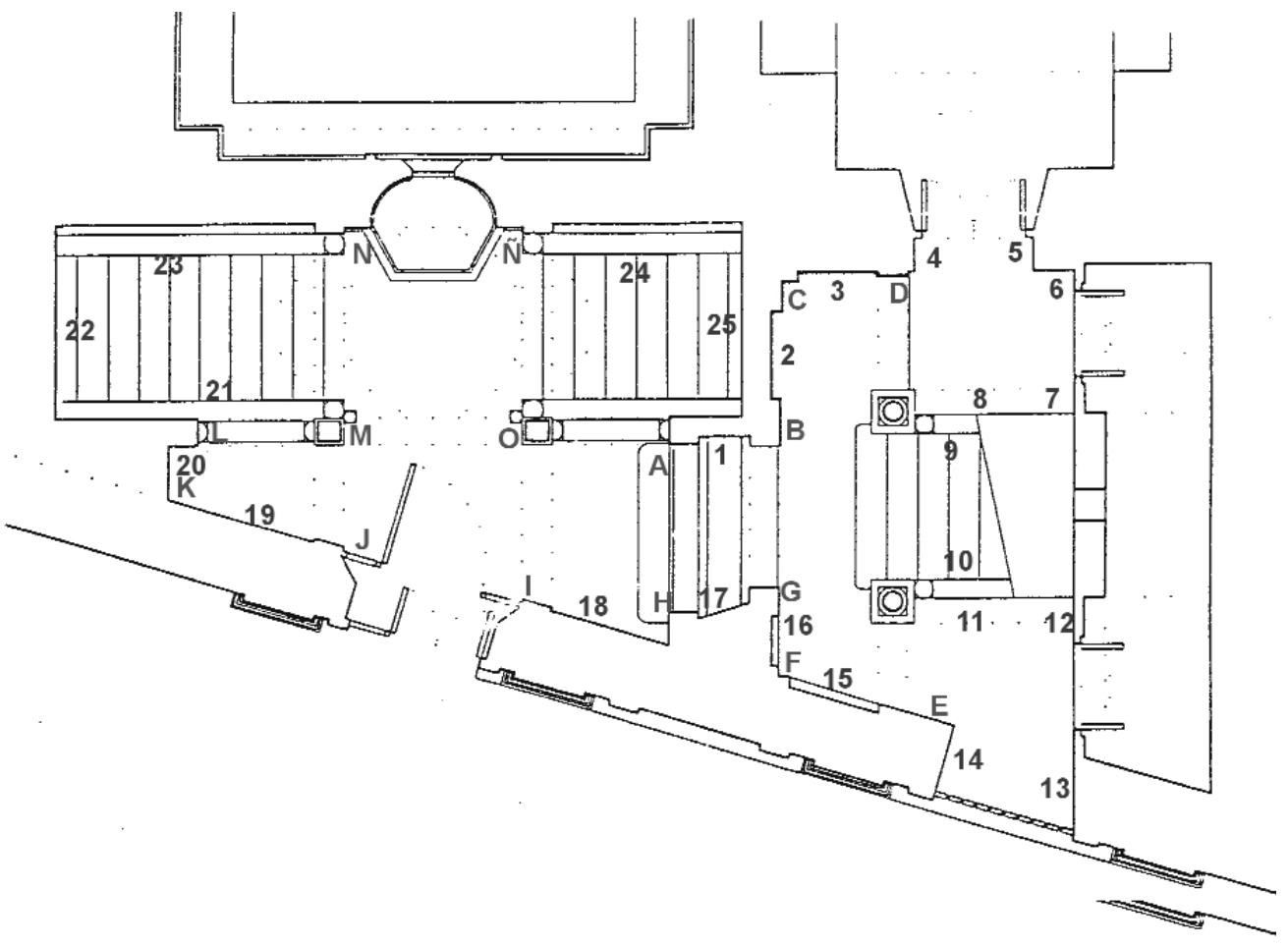

Tabla № 1 :

Decoración marmórea original. ÁMBITO DE ACCESO AL ORATORIO

\begin{tabular}{|c|c|c|c|c|}
\hline & Paramentos & Pilastras & Cornisas y molduras & Bóvedas \\
\hline Presencia & $95 \%$ de las catas & $100 \%$ de las catas & $100 \%$ de las catas & $100 \%$ de las catas \\
\hline Pérdidas & $\begin{array}{l}\text { Localización }{ }^{\star} \text { ): } \\
\mathrm{N}^{0} 2,3,4,6,15 \text { Y } 16 \\
\text { Causas: } \\
\text { Originadas por obras } \\
\text { de acondicionamiento } \\
\text { (rozas, reparaciones, etc) }\end{array}$ & $\begin{array}{l}\text { Localización }{ }^{\star}{ }^{\star} \text { : } \\
\text { Pilastra } \mathrm{E} \\
\text { Causas: } \\
\text { Falta de adhesión } \\
\text { de los estratos } \\
\text { superficiales que ha } \\
\text { originado pérdidas } \\
\text { puntuales. }\end{array}$ & & $\begin{array}{l}\text { Localización: } \\
\text { Lunetos de la bóveda } \\
\text { central de crucería } \\
\text { Causas: } \\
\text { Originadas por obras de } \\
\text { acondicionamiento }\end{array}$ \\
\hline $\begin{array}{l}\text { Porcentaje } \\
\text { estimado }\end{array}$ & $\begin{array}{l}70 \text { a } 75 \% \text { de la } \\
\text { superficie }\end{array}$ & $\begin{array}{l}95 \% \text { de la } \\
\text { superficie }\end{array}$ & $\begin{array}{l}95 \text { a } 100 \% \text { de la } \\
\text { superficie }\end{array}$ & $\begin{array}{l}90 \% \text { de la } \\
\text { superficie }\end{array}$ \\
\hline
\end{tabular}

Tabla N ${ }^{0} 2$ :

\begin{tabular}{|c|c|c|c|c|}
\hline & Paramentos & Pilastras y pilares & Cornisas & Cúpula y Bóvedas \\
\hline Presencia & $\begin{array}{l}\text { No aparece en el } \\
100 \% \text { de las catas }\end{array}$ & $100 \%$ de las catas & $\begin{array}{l}\text { No aparece en el } \\
100 \% \text { de las catas }\end{array}$ & $\begin{array}{l}\text { No aparece en el } \\
100 \% \text { de las catas }\end{array}$ \\
\hline Pérdidas & & & & \\
\hline $\begin{array}{l}\text { Porcentaje } \\
\text { estimado }\end{array}$ & $\begin{array}{l}0 \% \text { de la } \\
\text { superficie }\end{array}$ & $\begin{array}{l}95 \text { al } 100 \% \text { de la } \\
\text { superficie }\end{array}$ & $\begin{array}{l}0 \% \text { de la } \\
\text { superficie }\end{array}$ & $\begin{array}{l}0 \% \text { de la } \\
\text { superficie }\end{array}$ \\
\hline
\end{tabular}


$\longleftarrow$
늠

Foto 4. Pérdida de decoración marmórea

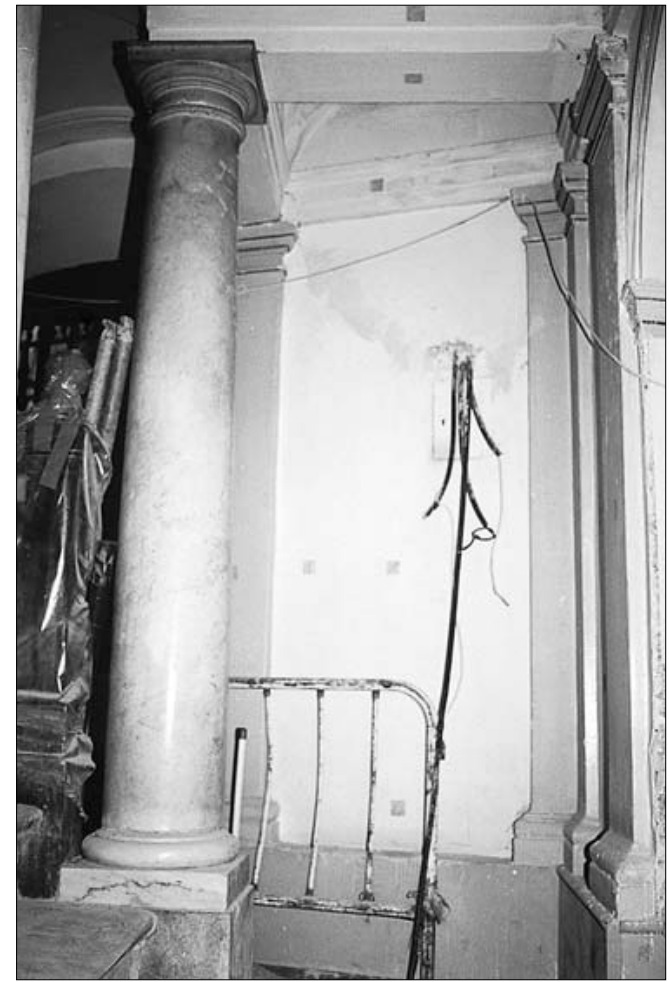

Tabla № 3 :

\begin{tabular}{|c|c|c|c|}
\hline \multicolumn{4}{|c|}{ Test de disolventes. Decoración blanca-grisácea (paramentos y bóveda) } \\
\hline $\mathrm{N}^{0}$ de prueba & Disolvente & Aplicación & Observaciones \\
\hline 1 & $\begin{array}{l}\text { Agua + Etanol } \\
(1: 1)\end{array}$ & Hisopo & $\begin{array}{l}\text { Elimina los estratos insistindo } \\
\text { No afecta a la decoración marmórea. }\end{array}$ \\
\hline 2 & Agua & $\begin{array}{l}\text { Papeta con papel } \\
\text { celulósico. Hisopo }\end{array}$ & Elimina el estrato blanco \\
\hline & Etanol & Hisopo & $\begin{array}{l}\text { Elimina el estrato grisáseo } \\
\text { adecuadamente. } \\
\text { No afecta al marmoreado. }\end{array}$ \\
\hline 3 & $\begin{array}{l}\text { Agua + acético } \\
(1: 1)\end{array}$ & Hisopo & $\begin{array}{l}\text { Eliminación de los estratos blanco } \\
\text { y grisáceo. }\end{array}$ \\
\hline 4 & & $\begin{array}{l}\text { Mecánicamente } \\
\text { con bisturí }\end{array}$ & Afecta a la decoración marmórea. \\
\hline
\end{tabular}

Con este estudio se ha podido conocer la composición decorativa de los estucos marmóreos, y a partir de ello ha sido posible la reconstrucción estética de todo el ámbito arquitectónico.

Descripción de la decoración marmórea en la escalera de subida al oratorio.

- Paramentos y bóvedas. Los marmoreados forman juegos de recuadros. Destaca el centro en tonos rosa-anaranjado con "filo o fileteado" en rojo óxido y borde marmoreado en tonos tierras, rojos y ocres.

- Zócalo. Marmoreado rojo oscuro.

- Pilastras y cornisas. Marmoreado amarillo veteado en gris y aplicación de veladura de color tierra.
Descripción de la decoración de la escalera de acceso a la cripta.

- Paramentos, cúpula y cornisas. Recubrimiento decorativo gris.

- Pilares y pilastras. Estuco marmóreo amarillo veteado en gris.

3. Evaluación del porcentaje de la decoración original subyacente a la actual

Con el objeto de poder determinar un porcentaje aproximado de la decoración marmórea original, fueron realizadas un total de 75 catas de $5 \times 5 \mathrm{~cm}$ en los diferentes elementos que conforman el ámbito de entrada y escaleras de acceso a la cripta y al oratorio (Véase gráfico de localización de ámbitos estudiados).

La aplicación de esta metodología de trabajo ha permitido establecer una valoración del porcentaje de la decoración marmórea original, cuyo resultado se expone en las tablas $n^{\circ} \mid$ y 2 :

\section{Determinación del estado de conservación}

El estudio realizado ha definido también las alteraciones que actualmente afectan a la decoración marmórea subyacente empleándose para ello la siguiente metodología:

- Observación visual del estado de conservación de los paramentos en sus distintos acabados.

- Valoración del estado en que se encuentra la decoración marmórea subyacente, finalizado el estudio estratigráfico mediante catas.

Su realización ha permitido establecer las siguientes patologías que afectan a los paramentos en su conjunto, con especial interés, a la decoración marmórea original.

\section{Patologías detectadas:}

- Disgregación del mortero en zonas con humedades. Pulverulencia del estrato de decoración. Paramento de acceso al servicio

- Desgaste puntual del estuco marmóreo en el paramento lateral derecho del primer tramo de la escalera de acceso al oratorio. Paramento interior derecho de la escalera de acceso al Oratorio

- Perdida de todos los estratos decorativos en los paramentos intervenidos con obras de acondicionamiento en el ámbito de la escalera de acceso al Oratorio Alto - paredes y lunetos de las bóveda central de crucería- (Véase foto $\left.n^{\circ} 4\right)$.

Falta de adhesión y perdidas puntuales de los estratos marmóreos localizados en la pilastra colindante a la última ventana del vestíbulo de la escalera.

Fino cuarteado generalizado del estuco marmorizado que recubre las pilastras y pilares.

Pulverulencia de la capa gris subyacente al estrato superficial blanco en los paramentos del ámbito de acceso a la cripta. 
Realizando una valoración global de la decoración marmórea descubierta podemos concluir que en general presenta un buen estado de conservación. No obstante, podemos también afirmar, que la principal causa de alteración se ha derivado de las intervenciones de acondicionamiento llevadas a cabo en los paramentos con motivo de la nueva instalación eléctrica (regolas de canalización) las cuales han originado pérdidas en todos los estratos presentes.

\section{Test de disolventes y descripción de la metodo- logía para la remoción de la decoración actual}

Para poder definir la metodología de remoción más idónea a las características y necesidades tanto de los estratos a eliminar (superposiciones decorativas), como del la decoración marmórea original, ha sido necesario realizar test de disolventes en los diversos ámbitos de estudio a fin de definir el método de remoción y los disolventes y proporciones más adecuados. Los resultados de estas pruebas se recogen en las tablas $n^{\circ} 3$ y $^{\circ} 4$.

\section{Metodología de remoción:}

Tras las pruebas realizadas, el método que se ha mostrado más idóneo para la eliminación de los estratos blanco y gris ha consistido en (Prueba $\mathrm{N}^{\circ} 2$ ):

- Papeta de papel celulósico impregnada con agua durante I minuto. Seguidamente aplicación de agua mediante hiposo para la remoción del estrato blanco superficial.

- Eliminación del estrato grisáceo mediante hisopo impregnado en etanol.

\section{Metodología de remoción}

La decoración marmórea que recubre pilastras, molduras y cornisas presenta escasa resistencia a la aplicación de disolventes debido a su técnica de veladuras al temple.

El método que se ha mostrado más idóneo par eliminar los estratos superpuestos sin que afecte al marmorizado original ha sido el siguiente (prueba $n^{\circ} 6$ ):

- Papeta de papel celulósico impregnada con etanolagua (I:I) durante 5 minutos.

- Eliminación mecánica mediante espátula de madera.

En el ámbito de entrada y acceso a la cripta para la remoción del estrato ocre verdoso que recubre pilares, pilastras, y cornisas es necesaria la utilización de disolventes más enérgicos, si bien se ha comprobado que afectan al estrato marmóreo subyacente, por lo que la metodología mas apropiada consiste en la eliminación mecánica con bisturí.

\section{Propuesta de intervención}

Los resultados de los estudios preliminares efectuados hasta el momento nos permiten disponer de criterios suficientes para definir la intervención más conveniente a estos espacios arquitectónicos. La propuesta de recuperación de la decoración original que a continuación

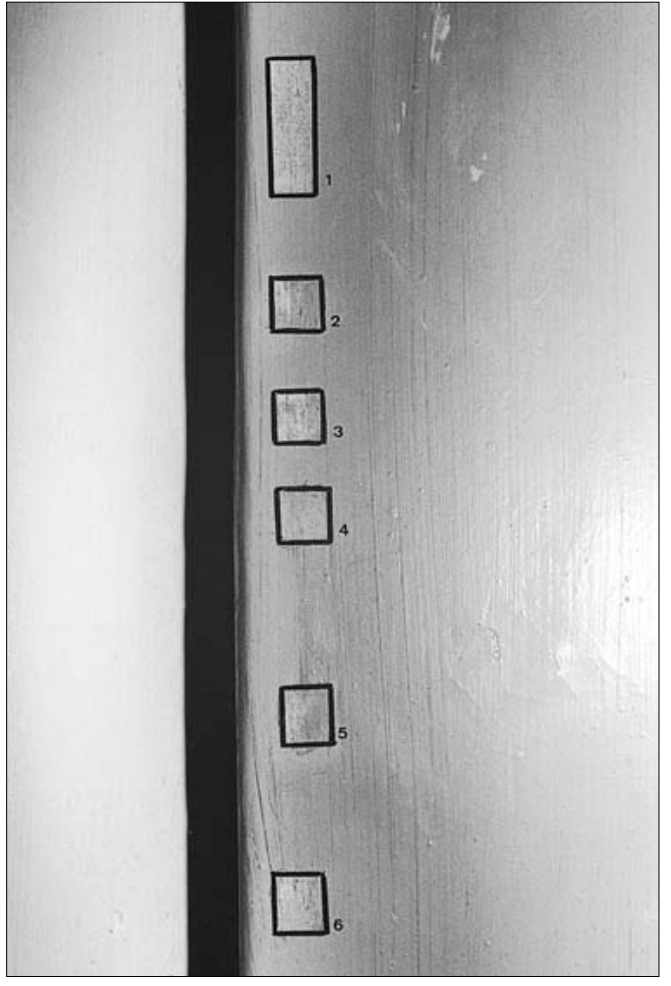

Tabla N ${ }^{\circ} 4$ :

\begin{tabular}{|c|c|c|c|}
\hline $\mathrm{N}^{0}$ de prueba & Disolvente & Aplicación & Observaciones \\
\hline 1 & & $\begin{array}{l}\text { Mecánicamente } \\
\text { con bisturí }\end{array}$ & Buen resultado \\
\hline 2 & $\begin{array}{l}\text { Agua - Etanol } \\
(2: 1)\end{array}$ & Hisopo & Actúa poco \\
\hline 3 & Etanol & Hisopo & Afecta al marmorizado \\
\hline 4 & $\begin{array}{l}1^{\circ} \text { Etanol } \\
2^{\circ} \text { Agua }\end{array}$ & $\begin{array}{l}\text { Papeta de papel } \\
\text { celulósico }\end{array}$ & $\begin{array}{l}\text { Eliminación la decoración verde. } \\
\text { Actúa lentamente }\end{array}$ \\
\hline 5 & Agua - Etanol & $\begin{array}{l}\text { Papeta de papel } \\
\text { celulósico ( } 30 \text { Seg.) } \\
\text { Eliminacón mecánica } \\
\text { con espátula de madera }\end{array}$ & $\begin{array}{l}\text { Afecta a la decoración marmórea. } \\
\text { Actúa bien. No afecta al marmorizado }\end{array}$ \\
\hline 6 & $\begin{array}{l}\text { Agua - Etanol } \\
(1: 1)\end{array}$ & $\begin{array}{l}\text { Papeta de papel } \\
\text { celulósico ( } 5 \text { Seg.) } \\
\text { Eliminacón mecánica } \\
\text { con espátula de madera }\end{array}$ & $\begin{array}{l}\text { Eliminación más rápida sin afetar } \\
\text { a el marmorizado }\end{array}$ \\
\hline
\end{tabular}

exponemos para cada uno de los ámbitos de estudio (acceso al Oratorio Alto y descenso a la Cripta) está basada en los siguientes motivos:

I. Se conserva un porcentaje muy elevado de decoración original, oscila entre un $70 \%$ al $95 \%$

2. El original se encuentra en un óptimo estado de conservación.

3. La eliminación de los estratos superpuestos es factible con métodos simples que no afectan al estrato original. 


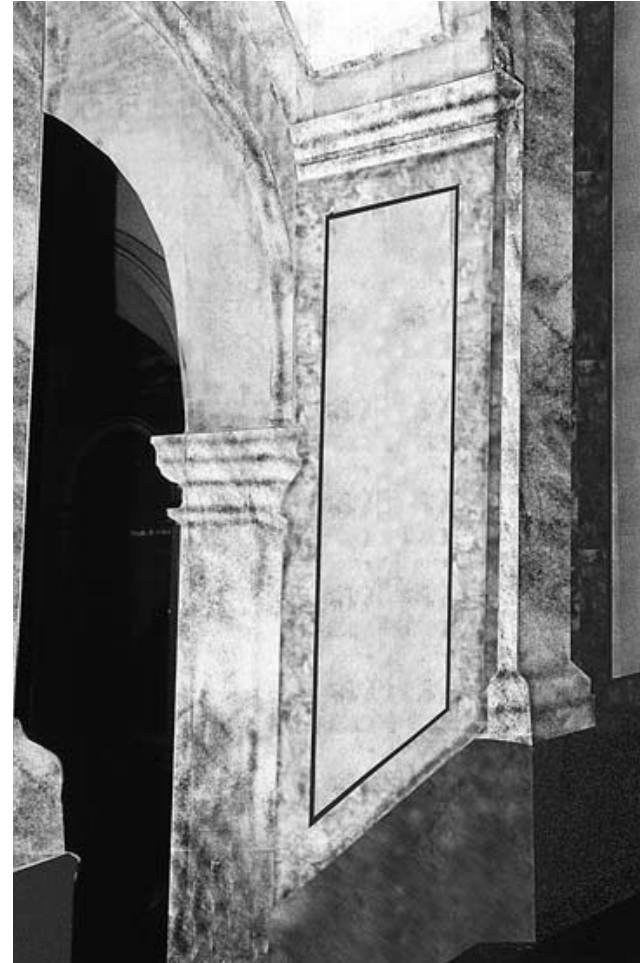

Foto 6. Reconstrucción de la decoración original
4. La recuperación de la decoración original contribuye a la lectura y puesta en valor de estos espacios en la integridad del conjunto arquitectónico, ya que existen otros ámbitos del inmueble en los que se conserva (Sacristía, Oratorio Alto, tramo superior de la escalera, etc.). 5. Los estratos superpuestos monocromos (realizados con pintura sintética) de reciente factura no presentan ningún valor documental ni histórico.

6. Los estudios efectuados documentan pormenorizadamente la evolución decorativa de los espacios estudiados.

Por todo ello creemos justificado proponer la siguiente intervención:

\section{Ámbito de acceso al oratorio}

- Recuperación de la decoración marmórea subyacente existente en todos los elementos arquitectónicos (paramentos, pilastras, bóvedas, cornisas y molduras).

- Consolidación de los morteros que presentan problemas de adhesión con productos afines a la naturaleza del mortero.

- Reintegración cromática de las perdidas y desgastes mediante técnica reversible y diferenciable.
- Finalizada la intervención de remoción de la decoración superpuesta se determinará la necesidad o no de aplicar una capa de protección final sobre los estucos marmóreos. Como posible protectivo se propone la utilización de resina acrílica Paraloid B-72 al 3\% en tolueno.

\section{Entrada y ámbito de acceso a la cripta}

- Recuperación de la decoración marmórea localizada en pilares y pilastras.

- Debido a la inexistencia de decoración marmórea y el escaso interés de los estratos subyacentes que presentan paramentos, bóvedas y cúpula en este ámbito se propone que el arquitecto director de la intervención en este inmueble evalúe la realización de un nuevo acabado, que mantenga la composición del conjunto decorativo recuperado o la reconstrucción de este espacio sobre la base de la decoración marmórea aparecida en la escalera de acceso al Oratorio.

\section{Conclusión}

El estudio de estratigráfico y de correspondencia aplicado al estudio de decoraciones pictóricas en un inmueble se demuestra de utilidad tanto para establecer la secuencia decorativa presente como, definir su porcentaje y estado de conservación, y lo más impotente, para definir los criterios y propuesta de intervención que requiere sobre la base de los resultados extraídos.

Para finalizar este artículo creemos ilustrativo mostrar la reconstrucción de la decoración marmórea de uno de los paramentos estudiados mediante el tratamiento informático de la imagen digitalizada.

Bibliografía:

A.A.V.V.: 1994: La obra en yeso policromado de los Corrales de Villalpando. Ministerio de Cultura, Dirección General de Bellas Artes y Archivos, Instituto de Conservación y Restauración de Bienes Culturales. Madrid.

ANTÓN SOLÉ, P.: La Santa Cueva de Cádiz. Edita Caja San Fernando de Sevilla y Jerez. Sevilla.

FRAZZONI, D: 1975: L'imbianchino Decoratore- Estuccatore. Editore Ulrico Hoepli. Milano.

GÁRATE ROJAS, l.: 1993: Artes de la Cal. Ediciones de la Universidad de Alcalá de Henares. Ministerio de Cultura, Dirección General de Bellas Artes y Archivos. I.C.B.R.B.C. Madrid.

PASQUAL DÍEZ, R: I785: Arte de hacer el estuco, o de imitar los jaspes. Imprenta Real. Madrid.

R. PARENTI. "La aplicación del método estratigráfico para el análisis de monumentos". En Cuaderno Patrimonio y Ciudad. Consejería de Cultura, Junta de Andalucía. IAPH., 1994., p: 58-66.

GARCÍA RAMOS, R. "Examen material de la obra de arte. La correspondencia de policromías". Boletín PH, n 12, 1995, p: 52-57.

GONZÁLEZ LÓPEZ, Ma J. "Metodología de estudio de correspondencia de capas polícromas aplicado al conocimiento de la escultura en madera policromada". Boletín PH, n 8. 1994, p: 10-13 